University of Nebraska - Lincoln DigitalCommons@University of Nebraska - Lincoln

US Army Research

U.S. Department of Defense

2011

\title{
Leader character, ethos, and virtue: Individual and collective considerations
}

Sean T. Hannah

West Point-United States Military Academy, sean.hannah@usma.edu

Bruce Avolio

University of Nebraska - Lincoln, bavolio@u.washington.edu

Follow this and additional works at: http://digitalcommons.unl.edu/usarmyresearch

Hannah, Sean T. and Avolio, Bruce, "Leader character, ethos, and virtue: Individual and collective considerations" (2011). US Army Research. 263.

http://digitalcommons.unl.edu/usarmyresearch/263

This Article is brought to you for free and open access by the U.S. Department of Defense at DigitalCommons@University of Nebraska - Lincoln. It has been accepted for inclusion in US Army Research by an authorized administrator of DigitalCommons@University of Nebraska - Lincoln. 
Discussion

\title{
Leader character, ethos, and virtue: Individual and collective considerations
}

\author{
Sean T. Hannah ${ }^{\mathrm{a}, *}$, Bruce J. Avolio ${ }^{\mathrm{b}, 1}$ \\ a Center for the Army Profession and Ethic, West Point-United States Military Academy, 646 Swift Road, West Point, NY 10996, USA \\ b Center for Leadership E' Strategic Thinking, University of Washington, Management and Organization Department, Box 353200, Seattle, WA 98195-3200, USA
}

\section{A R T I C L E I N F O}

Available online 19 August 2011

\begin{abstract}
A B S T R A C T
We advance the discussion that each leader has a moral component that can be defined as character that is distinct from values, personality, and other similar constructs. We seek to clarify what underpins forms of character-based leadership and exemplary leader behaviors. We build out our previous discussion (Hannah \& Avolio, this issue) that the locus of character is within the leader and is an integral part of the leader's self-system. Further, we extend the domain of character research toward its upper bounds and introduce the notion of ethos as a distinct class of character and relate ethos to extra-ethical virtuous behaviors. Finally, we place character in relationship to collectives and discuss bidirectional influences operating between leader character and the context.
\end{abstract}

Published by Elsevier Inc.

It isn't worthwhile...to dictate to gentlemen. Most of these things that need legislation they will, no doubt, easily find for themselves. Plato, Republic IV

\section{Introduction}

In "Character-Based Leadership, Context and Consequences," Quick and Wright (2011-this issue) examined the five questions that we raised in Hannah and Avolio (2011-this issue) that attempted to refine the conceptualization of leader character. Together in this dialog, we are beginning to clarify what constitutes the type of internally-driven strength of character discussed by Plato in the opening epigraph, albeit from slightly different perspectives.

In our final contribution in this Letters series on leader character we seek to accomplish three things. First, we further clarify our position on the relationship between character and personality as well as our concept of character signatures. Second, we address Quick and Wright's discussion of the metaphysical aspects of leader character and the concept of the leader-in-practice. Third, we propose new directions for character theory and research in leadership. These new directions include studying the relationship of character to extra-ethical or virtuous behavior and the inclusion of ethos as a super-ordinate class of character. Further, we propose that future research should incorporate the interactive processes occurring between leader character and the collectives those leaders interact with, while also taking into consideration the dynamic nature of the context in which these interactions transpire.

\section{Clarifications and responses}

\subsection{Character is not personality}

We agree with Quick and Wright that character is not personality. In Hannah and Avolio (2011-this issue), we suggested that character may be structured and operate like personality, but did not intend to equate the two, at least not with the common static,

\footnotetext{
* Corresponding author. Tel.: +1845 4968747.

E-mail addresses: Sean.hannah@usma.edu (S.T. Hannah), bavolio@u.washington.edu (B.J. Avolio).

1 Tel.: + 12065434367 .
} 
trait-based notions of personality. Instead, like more dynamic models of personality (e.g., Mischel \& Shoda, 1998; Wood, 2007) we suggest that character represents a layered, complex hierarchical structure. We suggest that character should be viewed as being integrated within a leader's identity and therefore differentiated across a complex identity structure that is developed across a leader's life-span as the leader interacts and learns from assuming various social roles (Hannah, Avolio, \& May, 2011).

Character is then represented across uniquely differentiated self-structures that are associated with each of those social roles, with each representing distinct facets of one's character (Hannah, Woolfolk, \& Lord, 2009; Lord, Hannah, \& Jennings, 2011). As aspects of character vary across identity or social roles, it results in some degree of variation in how an individual behaves in different roles and contexts. The application of these different self structures creates cross-situational variance in behaviors as various character identity facets are activated or suppressed as part of the working self over time. For example, a leader may have greater strength of character as reflected in their level of honesty when operating in their role as an internal team leader versus as a corporate spokesperson talking with financial analysts.

As each role or facet is primed, we will see the activation of different character signatures (Hannah \& Avolio, 2011-this issue) that can influence the behavior and choices that are made by a leader. Incorporating this type of variation in how we interpret a leader's character can help explain how leaders in one situation behave with what others might ascribe as 'the highest level of character', while in another situation the leader's behavior might seem suspect. Of course, we are not suggesting that there aren't leaders who can behave consistently across all situations; we are simply putting forth a framework to explain the range of character strengths and how we can explain variation in the way a leader behaves when it arises.

Further, based on Hannah and Avolio (2010) model of moral potency, we suggested that constructs of moral efficacy, moral ownership, and moral courage are also loci of character-based leadership and thus need to be considered. Again, we do not necessarily equate these constructs with character, but they do operate within the leader's self-system along with personality to influence ethical choices and whether and how choices translate into behavior. These constructs thus also need further discrimination from the construct of character.

\subsection{Character profiles and signatures}

Next, we distinguish our conceptualization of “character signatures” from Wright and Quick's (2011-this issue) concept of "character profiles". We do think both can coexist as applicable constructs. Wright and Quick's research suggested that there are profiles of character strengths possessed by individuals in certain occupations, or deemed necessary for those occupations. We agree that may be so. Valor, for example is likely more required for Soldiering or fire fighting than for the performing arts or sales. Our conceptualization of character signatures takes a less normative approach and is therefore more dynamic and elastic, based on our position that character is part of a dynamic self-system.

Specifically, Wright and Quick found patterns of various character strengths, what they call profiles, across occupations. Perhaps getting more granular, we also propose that leaders will further differentiate those strengths across identity facets within and between occupations. The character signature then is a temporary structure, primed as part of the leader's working self as they interact with their environment and the challenges faced (Lord et al., 2011). This parallels Mischel and Shoda's (1998) notion of a "personality signature" in discussing the dynamic nature of personality (cf., Shoda, LeeTiernan, \& Mischel, 2002). Therefore, two leaders may have similar overall character profiles when responding to survey questions that ask them to rate their overall self as the referent, as is commonly used in character research. Yet, the same two leaders may differ extensively on how they structure their strengths across identity facets, and thus the two may behave quite differently depending on the context. This suggests that researchers should measure character across identity facets/social roles, using methods such as those recommended by Hannah and Avolio (2010) to measure moral potency across leaders' identities.

\subsection{The leader-in-practice and metaphysical basis}

We read with interest Quick and Wright's (2011-this issue) notion of the leader-in-practice and their position that the field should consider that character may be in part metaphysical in nature. We fully agree with their position that as leaders "practice," their interactions with the context and other people will influence the development and activation of character, which we take up in a following section. Quick and Wright suggested that during such social interactions the manifestation of character in the leader may stem in part from loci other than physical.

We agree that character cannot be fully reduced with current research methods, and thus from an epistemological perspective, character remains a fuzzy construct requiring further analysis. The physical sources of character have yet to be adequately explored, and we suggest that better defining those sources should be the first place to start. It is possible, for example, that emerging research on embodied cognitions (e.g., Lord \& Shondrick, 2011-this issue; Niedenthal, Winkielman, Mondillon, \& Vermeulen, 2009) may shed light on whether there is an affective and possibly even a physiological basis for leader character. This might include a visceral experience that accompanies an extreme level of character, or what we refer to as ethos in certain situations. Further, advancements in measuring implicit cognitions such as the Implicit Association Test (Greenwald, Nosek, \& Banaji, 2003) may enable us to assess the less tangible aspects of character by assessing leaders' relevant cognitive associations that may in part underpin character. Just as research has moved beyond Max Weber's early notions of charisma being defined as "God given", we think we can find ways to operationalize character. Perhaps building on Quick and Wright's concerns, we suggest that the study of character will advance to the extent we are open to alternative methodologies that range from neurological assessments to sociological measures of the dynamic nature of uncertain contexts. 


\section{Extending conceptualizations of character}

\subsection{Beyond ethical behavior - ethos and virtue}

The study of ethics and leadership has generally been limited to a narrow 'criterion space,' focused on predicting a limited span of ethical behaviors and identifying predictors that influence that narrow band of criteria. The construct of ethical leadership as operationalized by Brown, Treviño, and Harrison (2005), for example, is based on a transactional base, what they call a moral manager, where the leader disciplines unethical behavior, rewards integrity, establishes ethical norms, and takes similar actions to promote ethical behaviors in followers. We believe that the leadership field should more fully investigate the criterion space that lies beyond transactional ethical behavior-what we might call extra-ethical, or simply virtuous behavior.

We do recognize that there has been some attempts to 'stretch' the criterion space thru the various works on extra-role or organizational citizenship behaviors (Smith, Organ, \& Near, 1983). While this work has broadened the criterion range a bit, we submit there still remains an extensive range of meaningful constructs that have been untapped in prior research. For example, what makes a Soldier brave enemy fire to drag a wounded comrade out of harm's way? Much as the leadership field began to differentiate transactional from transformational leadership over two decades ago seeking to determine what predicts "performance beyond expectations" (Bass, 1985), we argue that a similar focus is needed to predicting "ethics beyond expectations".

Our thinking parallels that of the work conducted on typical versus maximum performance, which has attempted to extend the space or range of performance constructs into their upper limits where predictors may not exactly operate the same as lower down the criterion space (DuBois, Sackett, Zedeck, \& Fogli, 1993; Sacket, Zedeck, \& Fogli, 1988). This work suggests that the relationship between a given predictor and a performance criterion may be non-linear such that the relationship changes across the range of the criterion variable. While mere extrinsic motivation, for example, may well predict basic ethical compliance to a point, we would not expect it to predict higher levels of more self sacrificing virtuous behavior. We suggest that what caused Secret Service agents to shield President Reagan under fire with their own bodies, what we will argue is an extreme level of character called ethos, is qualitatively different from what predicts less intense ethical actions or less extreme contexts.

\subsection{Ethos}

In the context of rhetoric, in the Nicomachean Ethics (Rackham, 1926) Aristotle stated that ethos comes from possessing high levels of three components: phronesis (practical skills and wisdom), arête (virtue and goodness), and eunoia (goodwill toward others). Hannah, Campbell, and Matthews (2010) stated that the term ethos is commonly used in military, police, fire and other dangerous professions to represent the inner strength that compels individuals to "willingly endure the cognitive, emotional, and physical hardships normally associated with dangerous contexts-and if ultimately needed-to risk physical injury or death; all with little extrinsic reward." (p. 180). We suggest that ethos is not unique to dangerous contexts and may underpin a nurse's acts of extreme dedication and sacrifice or a lawyer declining a position at a high paying law firm to provide legal representation to the poor. Ethos suggests an extreme level of psychological (cognitive and emotional) and perhaps visceral physiological attachment to the target of ethos that is sufficient to drive virtuous behavior when such behavior is called for by the context. By target we mean patient care, serving the poor, protecting crime victims, saving a financial institution from its leader's greed or other purposes or domains a person seeks to serve.

As an underdeveloped theoretical construct, the ontological basis for ethos certainly needs to be refined and unpacked, as does the larger concept of character. At this early point in theory building, we suggest that ethos, as an inner strength driving virtue, should be considered as a distinct class of character-a class that when possessed by an individual will provide the inner strength or resources to step up and perform extra-ethical, virtuous action. Therefore, ethos is not represented by high scores on just any character measure. The measure itself must go beyond the mundane and contain content that taps into the highest range of character. If using survey items, for example, they must reflect virtuous action where self-sacrifice is required and the individual would have no reservations with such self sacrifice because it is part of their character identity or signatures.

\subsection{A framework for character, ethos, and virtue}

We provide a very general visual depiction of our thinking related to ethos and virtue in Fig. 1. As shown on the $y$ axis, ethical behavior is merely a mid point on the criterion range, with virtuous behavior representing the upper range, what we have defined as maximum ethical behavior. On the $x$ axis, a leader's character can range from low to high or extend into extremely high levelsethos. The shaded area of the figure denotes the limited theoretical space that current theories of ethics and leadership have developed. However, as clearly noted in our (Hannah \& Avolio, 2011-this issue; Wright \& Quick, 2011-this issue; Quick \& Wright, 2011-this issue) previous letters, much work remains to better determine how character operates within this space. As suggested by the inflection points shown on each slope, we suggest that non-linear relationships may occur as we move into the higher levels beyond more common transactional ethical behaviors, and within this range that ethos begins to operate.

Further, we use solid slopes in Fig. 1 to depict conditions of high moral intensity and dashed lines to represent conditions of low moral intensity (Jones, 1991). We suggest that a morally intense context may operate similar to a maximum performance context by creating non-linear effects on behavior as suggested by the varying slope lines shown in Fig. 1 (DuBois et al., 1993 ; Sacket et al., 1988). As depicted by the more positive slopes of the solid lines, we suggest that extremely high levels of character, 


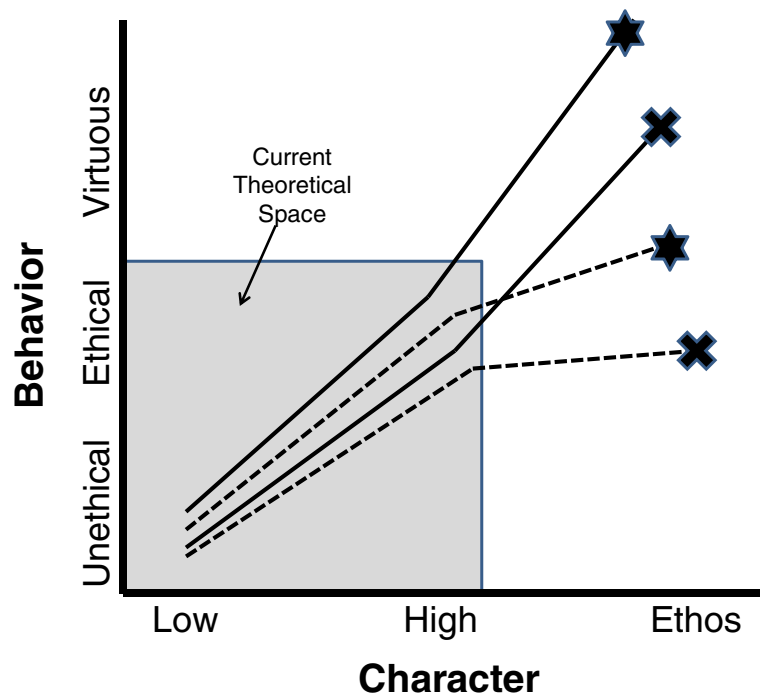

Notes:1)dashed line represent low moral intensity. Solid line represents high moral intensity. 2) Stars represent high collective character bolstering, crosses represent low bolstering.

Fig. 1. Character, virtuous behavior, moral intensity, and collective bolstering.

i.e., ethos will operate most forcefully under conditions of high moral intensity, where virtuous behavior is most called for, and indeed most needed. This reinforces Hannah and Avolio (2011-this issue) and Wright and Quick's (2011-this issue) position that high levels of character are required of leaders operating in extreme contexts (Hannah et al., 2010; Hannah, Uhl-Bien, Avolio, \& Cavarretta, 2009).

As suggested by the lesser slope of the dashed lines in Fig. 1, we suggest that ethos is less important under conditions of lower moral intensity. This is because lower levels of character may promote fairly similar action when perceived risk, potential adverse consequences, and other aspects of moral intensity are lower. A fire captain leading his firefighters into a burning house to save a trapped civilian, for example, may do so with average to high levels of character under conditions where the fire has not yet threatened the collapse of the structure and thus it is a more routine evacuation. Yet under a more intense ethical situation where the risk to that leader and his men is significant, we suggest that ethos will inspire virtuous behavior. Based on the discussion thus far, we offer the following working definition of individual level ethos.

3.4. Extreme levels of strength of character required to generate and sustain extra-ethical virtuous behavior under conditions of high moral intensity where personal risk or sacrifice is required in the service of others

Finally, we bring attention to the more positive slopes of the vectors noted by a star symbol shown in Fig. 1, as compared to those vectors noted by an X symbol. We propose that groups and other collectives can serve to bolster individuals' character, and we take up that discussion in the next section.

\subsection{Leader character and collective bolstering}

Thus far we and Wright and Quick (2011-this issue) have addressed character as an individual level phenomenon. We have argued that the locus of character is intra-individual and separate from a leader's behaviors, what we called character-based leadership or the transmission of character. We also made locus and transmission distinct from others' interpretations of those behaviors, or what we called the reception of character (Hannah \& Avolio, 2011-this issue). While the locus of character is the individual, however, it is not disconnected from the collectives with whom an individual interacts. This interdependency was also noted in Quick and Wright's (2011-this issue) discussion of the leader-in-practice who learns through observation, diagnosis, and interpretation. Therefore, future research should investigate the contingencies and causations that collectives impose on leader character and vice versa.

First, leaders likely develop their character in large part through social learning. Groups, like individuals, develop collective norms that influence the moral thinking and action of other group members (Power, Higgins, \& Kohlberg, 1989). Group and individual character are likely reciprocally related, with each influencing the other across levels through mechanisms such as organizational climate and culture (Selznick, 1992). Morgeson and Hofmann (1999, p. 252) explain that such emergence occurs through a series of social interactions, which "forms the basis for the eventual emergence of collective constructs." Similarly, Weick (1979) argued that individual behaviors within organizations do not occur in isolation, but rather occur through connecting events he called "double interacts", such as person A initiating a behavior that then influences person B's behaviors; which in turn serves 
to reciprocally shape person A's behavior in return. Morgeson and Hofmann (1999, p. 252) describe the double interact as being, "the basic building block upon which all larger collective structures are composed."

Collectives can "bolster" the character of their leaders through various social learning and social identity processes. For example, as a group develops shared beliefs about character, these shared beliefs may become part of the group's scripts for expected actions when virtue is called for (Hofmann \& Jones, 2005). These collective scripts can then serve to guide individual actions and be taught to new members as the 'correct' way to act (Hinds \& Mortensen, 2005), which becomes part of their self structures and character signatures. This suggests that leaders and groups develop collective norms or signatures for expected virtuous behavior, which then guides the behavior of others (Power et al., 1989). We therefore suggest that context as described above should be considered in models of character as well as aspects of reciprocal causation.

\section{Agreements and agreements to disagree}

The concept of character has been discussed since Aristotle and the ancients (Rackham, 1926), yet is an emerging construct in the psychological and organizational sciences as far as developed theories and measures. We our thankful to our partners Tom Wright and Jim Quick who inspired us in dialog in this Letters series to jointly refine the theoretical basis and practical usage of character, while also suggesting ways to develop and measure this construct. This dialog across four letters has raised many points of agreement and a few points of difference.

We mutually agree that each leader has a moral component that can be defined as character that is distinct from values, personality, and other similar constructs. Additionally, we are aligned in belief that the study of character is needed if we are to understand what underpins forms of character-based leadership, and that future character research can help identify antecedents to virtuous leader behaviors. We all agree that character can be developed and that the locus of character is within the leader, and thus there is a need to unpack the locus, transmission, and reception phases that occur as a leader displays character in interactions with others. Quick and Wright (2011-this issue) suggest an idiographic approach to doing so. Additionally, we mutually agree that character is contextually influenced and that differing sets of character strengths may be most fitting for specific contexts. Most notably, we have all echoed the importance of strong leader character in more extreme contexts.

We differ somewhat in our theorizing in that we have focused only on the physical locus of character. Further, we have taken a more compartmentalized approach to examining character that is based in self-complexity theory and dynamic self-systems. While we all agree context influences character, we have suggested that character dynamically varies across contexts, what we have called a character signature that activates in the working self; whereas Wright and Quick have assessed matches between leaders' character profiles and their occupation. Taking both approaches, future research can assess how character operates across and within occupational contexts. Overall, this dialog has produced many avenues for future research and we hope inspired scholars to take the opportunity and challenge to advance the study of what constitutes a leader's character.

\section{References}

Bass, B. M. (1985). Leadership and performance beyond expectations. New York: Free Press.

Brown, M. E., Treviño, L. K., \& Harrison, D. A. (2005). Ethical leadership: A social learning perspective for construct development and testing. Organizational Behavior and Human Decision Processes, 97, 117-134.

DuBois, C. L. Z., Sackett, P. R., Zedeck, S., \& Fogli, L. (1993). Further exploration of typical and maximum performance criteria: Definitional issues, prediction, and white-black differences. Journal of Applied Psychology, 78, 205-211.

Greenwald, A. G., Nosek, B., \& Banaji, M. (2003). Understanding and using the Implicit Association Test: An improved scoring algorithm. Journal of Personality and Social Psychology, 85, 197-216.

Hannah, S. T., \& Avolio, B. J. (2011). The locus of leader character. The Leadership Quarterly, 22, 979-983 (this issue).

Hannah, S. T., \& Avolio, B. J. (2010). Moral potency: Building the capacity for character-based leadership. Consulting Psychology Journal, 62, 291-310.

Hannah, S. T., Avolio, B. J., \& May, D. R. (2011). Moral Maturation and moral conation: A capacity approach to explaining moral thought and action. Academy of Management Review, 36.

Hannah, S. T., Campbell, D. J., \& Matthews, M. D. (2010). Advancing a research agenda for leadership in dangerous contexts. Military Psychology, 22, 157-S189.

Hannah, S., Uhl-Bien, M., Avolio, B., \& Cavarretta, F. (2009). A framework for examining leadership in extreme contexts. The Leadership Quarterly, 20, 897-919.

Hannah, S. T., Woolfolk, R. L., \& Lord, R. G. (2009). Leader self-structure: A framework for positive leadership. Journal of Organizational Behavior, 30, 269-290.

Hinds, P. J., \& Mortensen, M. (2005). Understanding conflict in geographically distributed teams: The moderating effects of shared identity, shared context, and spontaneous communication. Organization Science, 16, 290-307.

Hofmann, D. A., \& Jones, L. M. (2005). Leadership, collective personality, and performance. Journal of Applied Psychology, 90, 509-522.

Jones, T. M. (1991). Ethical decision-making by individuals in organizations: An issue-contingent model. Academy of Management Review, $16,366-395$.

Lord, R. G., \& Shondrick, S. J. (2011). Leadership and knowledge: Symbolic, connectionist, and embodied perspectives. The Leadership Quarterly, 22, 207-222 (this issue).

Lord, R. L., Hannah, S. T., \& Jennings, P. L. (2011). A framework for understanding leadership and individual requisite complexity. Organizational Psychology Review, 1(2), 104-127.

Mischel, W., \& Shoda, Y. (1998). Reconciling processing dynamics and personality dispositions. Annual Review of Psychology, 49, $229-258$.

Morgeson, F. P., \& Hofmann, D. A. (1999). The structure and function of collective constructs: Implications for multilevel research and theory development. Academy of Management Review, 24, 249-265.

Niedenthal, P. M., Winkielman, P., Mondillon, L., \& Vermeulen, N. (2009). Embodiment of emotion concepts. Journal of Personality and Social Psychology, 96, 1120-1136.

Power, C., Higgins, A., \& Kohlberg, L. (1989). The habit of the common life: Building character through democratic community schools. In L. Nucci (Ed.), Moral development and character education: A dialogue (pp. 125-143). Berkeley, CA: McCutchan.

Quick, J. C., \& Wright, T. A. (2011). Character-based leadership, context and consequences. The Leadership Quarterly, 22, 984-988 (this issue).

Rackham, H. (1926). Aristotle the Nicomachean Ethics with an English translation by H. Rackham. Boston: Harvard University Press.

Sacket, P. R., Zedeck, S., \& Fogli, L. (1988). Relations between measures of typical and maximum job performance. Journal of Applied Psychology, 73, 482-486.

Selznick, P. (1992). The moral commonwealth. Berkeley, CA: University of California Press. 
Shoda, Y., LeeTiernan, S., \& Mischel, W. (2002). Personality as a dynamical system: Emergence of stability and distinctiveness from intra-and interpersonal interactions. Personality and Social Psychology Review, 6, 316-325.

Smith, C. A., Organ, D. W., \& Near, J. P. (1983). Organizational citizenship behavior: Its nature and antecedents. Journal of Applied Psychology, 68, 653-663. Weick, K. E. (1979). The social psychology of organizing (2nd ed). New York: McGraw-Hill.

Wood, D. (2007). Using PRISM to compare the explanatory value of general and role-contextualized trait ratings. Journal of Personality, 75, 1103-1126.

Wright, T. A., \& Quick, J. C. (2011). The role of character in ethical leadership research. The Leadership Quarterly, 22, 975-978 (this issue). 